\title{
Investigation of longitudinal reinforcement contribution in shear punching of reinforced concrete flat slabs without transverse reinforcement
}

\author{
Vladimir Alekhin ${ }^{1,2,3, *}$, Alexander Budarin ${ }^{1}$, Maxim Pletnev ${ }^{1,2}$, and Liubov Avdonina ${ }^{1,2}$ \\ ${ }^{1}$ Institute of Civil Engineering and Architecture, Ural Federal University, 19, Mira st., Ekaterinburg, \\ 620002, Russia \\ ${ }^{2}$ TECHCON, 50a, Lenina st., Ekaterinburg, 620075, Russia \\ ${ }^{3}$ Ural Branch of the Russian Academy of Sciences, Science and Engineering Center "Reliability and \\ Safety of Large Systems and Machines", 91, Pervomayskaya st., Ekaterinburg, 620041, Russia
}

\begin{abstract}
The shear punching of the reinforced concrete slabs is a complex process occurring when considerable force is concentrated on the relatively small area of a column-slab connection. An incorrect assessment of load capacity of slab under the punching shear may lead to an accident. One of the most significant factors affecting the slab capacity is longitudinal reinforcement. In this article much attention is given to the analysis of the longitudinal rebar impact on the maximum loading capacity of reinforced concrete slabs without transverse reinforcement affected by punching shear force using the finite element method. The results obtained via the finite element simulation are compared with laboratory tests and manual calculations carried-out using various methods represented in different national building Codes of practice.
\end{abstract}

\section{Introduction}

At present, reinforced concrete is one of the most demanded and widely used building materials. The global volume of application of reinforced concrete structures is more than 2 million cubic meters per year. The amount of steel being used in the fabrication of steel structures is 2-3 times less than the amount of steel used in the production of reinforced concrete structures. Its scope of application is enormous.

The most common application of the reinforced concrete is the construction of frame structures for industrial and residential buildings. Extensive use is being made of a framework design with flat slabs. The main advantages of the application of this construction type are the savings in material, reduction of working hours for constructing the formwork, better insulation, and increased headroom. However, this design solution is

\footnotetext{
*Corresponding author: megg@bk.ru
} 
often affected by the punching shear of reinforced concrete slabs. Punching shear is a type of failure of reinforced concrete slab structures affected by forces and bending moments which are concentrated on a relatively small area. This type of failure is dangerous and unpredictable because no visible signs are shown prior to failure. In other words, the destruction of a slab has brittle nature and occurs unexpectedly. The Fig. 1 demonstrates this type of failure.
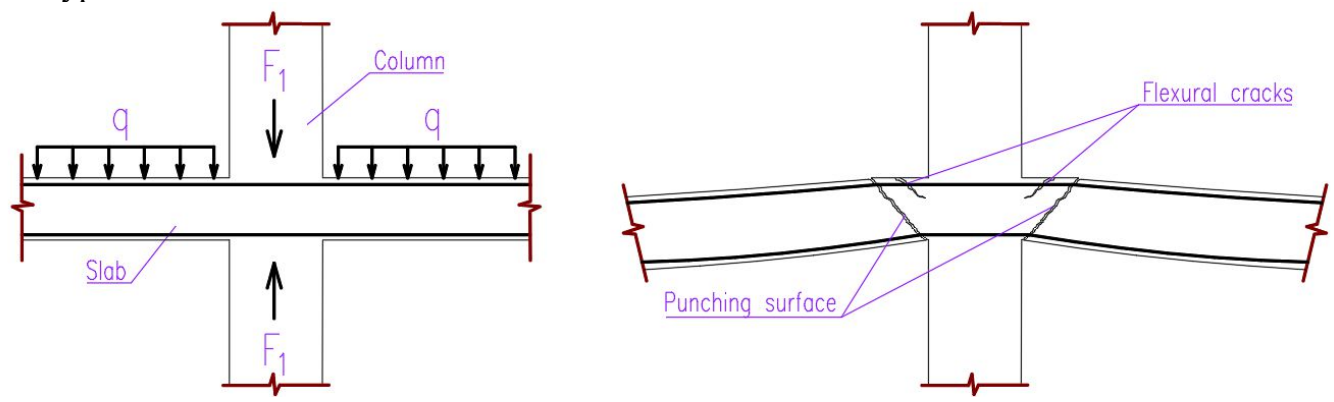

Fig. 1. A slab-column connection (left) and a punching shear failure (right)

Transverse reinforcement significantly improves the punching shear resistance of a flat slab. Nevertheless, installation of punching shear reinforcement is a time and money consuming process. Thus, modern engineers working with reinforced concrete structures were faced with challenge of assessing the punching shear resistance of a flat slab without transverse reinforcement. To estimate the punching shear capacity of a slab the engineer needs a reasonably accurate method. Different building codes of practice, currently used in various countries, suggest different approaches to the estimation of the punching shear resistance, which leads to vastly different outcome of calculations for the same structure affected by similar loads. The differences in the building codes of practice are mostly attributable to factors taken into account. One of the most significant and controversial factors is the influence of longitudinal reinforcement. For instance, in the Russian code of practice, SP 63.13330.2012 [1], this factor is not taken into account at all, while in Eurocode 2 [2] the longitudinal reinforcement is considered as an empirical function. The objective of this paper is the estimation of the influence of longitudinal reinforcement on the punching shear capacity of a flat reinforced concrete slab without transverse reinforcement using finite element method.

\section{Stress-strain state of a slab during the punching shear}

The work of a structure during the punching shear can be conditionally divided into three stress-strain stages. The first stage can be characterized by relatively small strains of concrete and reinforcement [3]. Meanwhile, the strain in the structure is almost entirely elastic. It is considered that the longitudinal reinforcement of reinforced concrete slabs without transverse reinforcement influences the duration of this stage through the shear resistance of uncracked concrete [4]. When the stress in the tensile area of concrete reaches the tensile strength value, the second stage of the stress-strain state of the structure starts. The second stage can be characterized by the beginning of the crack formation process in concrete. The first cracks occur on the top surface of the slab near the column. With the increase in the load, the formation of tangential cracks can be observed $[5,6]$.

When a crack in concrete is crossing longitudinal reinforcement a dowel action occurs. A dowel action is the ability of reinforcing bars to transfer forces perpendicular to their axis [7]. When loads reach levels close to the failure load value, the transition of the stress-strain state of the slab to the last stage, the failure stage, takes place. The failure of the slab 
subjected to the punching shear is followed by the creation of a punching pyramid that is limited by a critical perimeter.

Different national building Codes of practice suggest different approaches to the determination of the shape and size of the critical perimeter. The shape of the punching pyramid depends on the geometric properties of a slab and a column and the reinforcement of a slab.

\section{Finite-element analysis}

For the detailed investigation of the influence of longitudinal reinforcement on capacity and stress-strain state of a flat reinforced concrete slab without transverse reinforcement during the punching shear, the finite element model was created in ANSYS 19.0 software. This software package has a range of material models which allow the user to describe complex nonlinear behavior of reinforced concrete structures. To make sure that material models used in experiments provide for describing the behavior of a structure under applied load with sufficient accuracy, a verification test has to be carried-out. In other words, it is necessary to compare the results of the finite element simulation with the results of a laboratory experiment.

\subsection{Verification}

The results of the laboratory testing of a reinforced concrete slab subjected to the punching shear were used as a basis for a verification model [8]. The slab had dimensions of $1500 \times$ $1500 \times 125 \mathrm{~mm}$. The load was applied through the load-transferring steel plate that had dimensions of $130 \times 130 \mathrm{~mm}$. Q158 steel mesh was used as compression reinforcement. This mesh consists of $5.5 \mathrm{~mm}$ bars with $150 \mathrm{~mm}$ spacing in both directions. $14 \mathrm{~mm}$ diameter bars spaced at $110 \mathrm{~mm}$ intervals in both directions were used as tensile reinforcement. The reinforcement steel for both tensile and compressive zones had the following properties: tensile and compressive strength of $506 \mathrm{MPa}$, elastic modulus of $2 \times$ $10^{5} \mathrm{MPa}$, and Poisson ratio of 0.3 . The slab had the following protective layers of concrete: $15 \mathrm{~mm}$ on the tension side and $20 \mathrm{~mm}$ on compression side. Intermediate effective depth of the slab was $96 \mathrm{~mm}$. The concrete had compression strength of $52.4 \mathrm{MPa}$, tensile strength of $3.3 \mathrm{MPa}$, and elastic modulus of $3.56 \times 10^{4} \mathrm{MPa}$. During the laboratory test the slab was supported by a steel frame consisting of eight circular cross section steel columns. The slab was failed by punching shear at the load of $325.6 \mathrm{kN}$. The numerical model has the same material properties, boundary conditions, and geometry as the laboratory specimen. In the Fig. 3 the numerical model of the laboratory slab created in ANSYS software is shown.

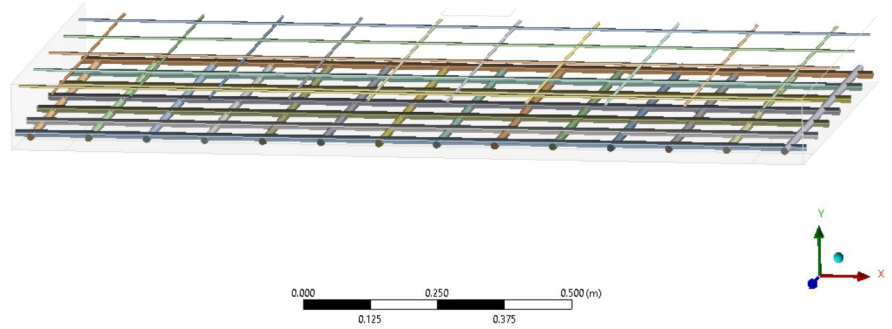

Fig. 3. Numerical model of the laboratory slab

The reinforcement is modeled using REINF264 3-D discrete elements. The Bilinear Isotropic Hardening model is used for describing nonlinear behavior of the reinforcement. Higher order 3-D 20-node solid elements SOLID186 are used for modeling the concrete. 
The linear form of hardening/softening function of the Drucker-Prager yield criterion describes nonlinear behavior of the concrete. The numerical model was also failed by means of the punching shear with force of $329.9 \mathrm{kN}$ that is very close to the critical load of the laboratory slab. The Fig. 4 shows equivalent plastic strain of the numerical model in the moment before failure.
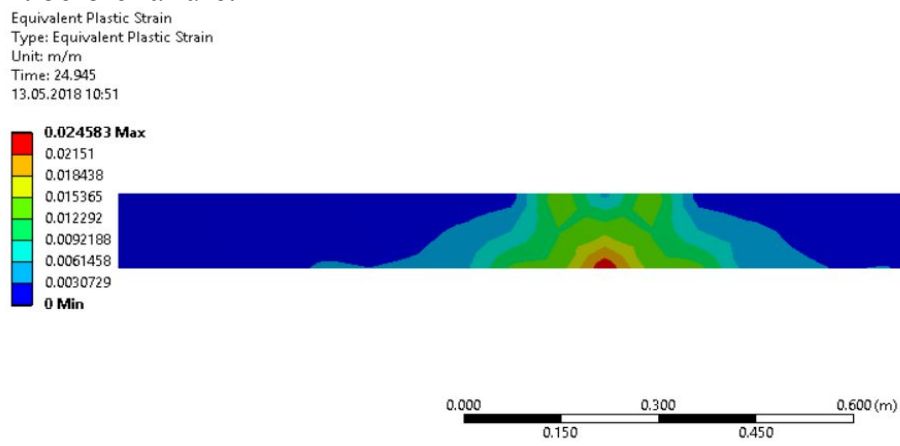

Fig. 4. Equivalent plastic strain of a numerical model in the moment before failure

Verification tests also allowed selecting the mesh size and convergence settings.

\subsection{Finite-element tests}

The series of four finite element experiments was conducted for assessing the influence of the longitudinal reinforcement on the punching shear capacity of a reinforced concrete slab without transverse reinforcement. Each numerical specimen was a slab with size of $1500 \times$ $1500 \times 150 \mathrm{~mm}$ based on eight round supports. The Fig. 5 shows the dimensions and reinforcement details of the numerical specimen.
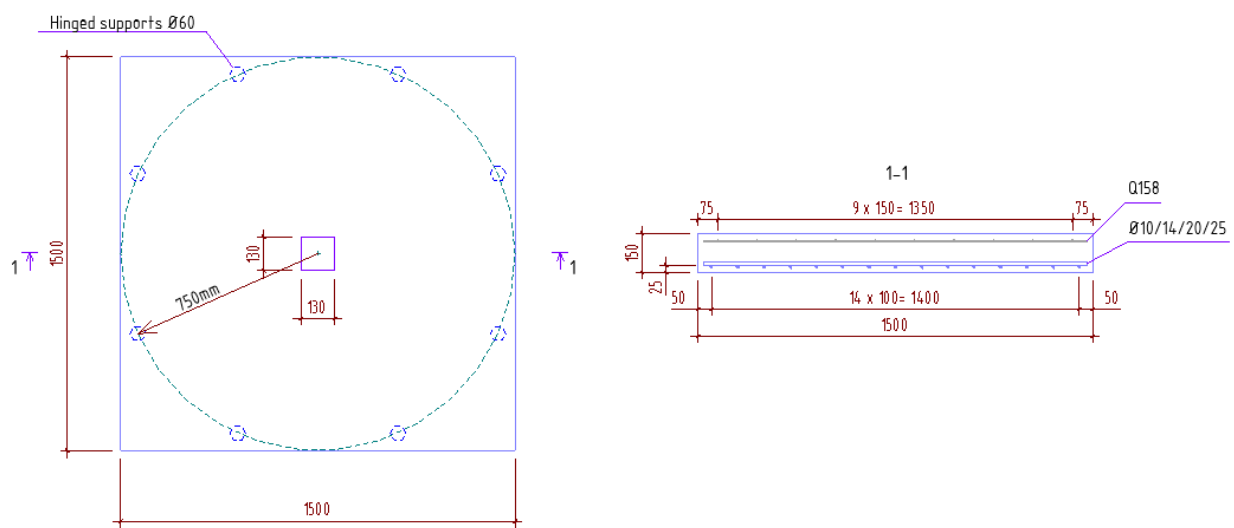

Fig. 5. Dimensions and reinforcement details of numerical specimens.

All slabs had the following material properties: concrete compression strength of 17 $\mathrm{MPa}$, tensile strength of $1.15 \mathrm{MPa}$, elastic modulus of $3,25 \times 104 \mathrm{MPa}$, and Poisson ratio of 0.2 . Compressive and tensile reinforcement had yield strength equal to $506 \mathrm{MPa}$, elastic modulus equal to $2 \times 105 \mathrm{MPa}$, and Poisson ratio of 0.3 . The compressive reinforcement was represented by Q158 steel mesh. 10/14/20/25 mm diameter bars spaced at $100 \mathrm{~mm}$ in both directions were used as a tensile reinforcement in different finite-element slabs respectively, i.e. the tensile reinforcement bars of different specimens had different sizes.

The effective depth of all specimens was $125 \mathrm{~mm}$. The Fig. 6 demonstrates the forcedeflection curves for different numerical slabs. 


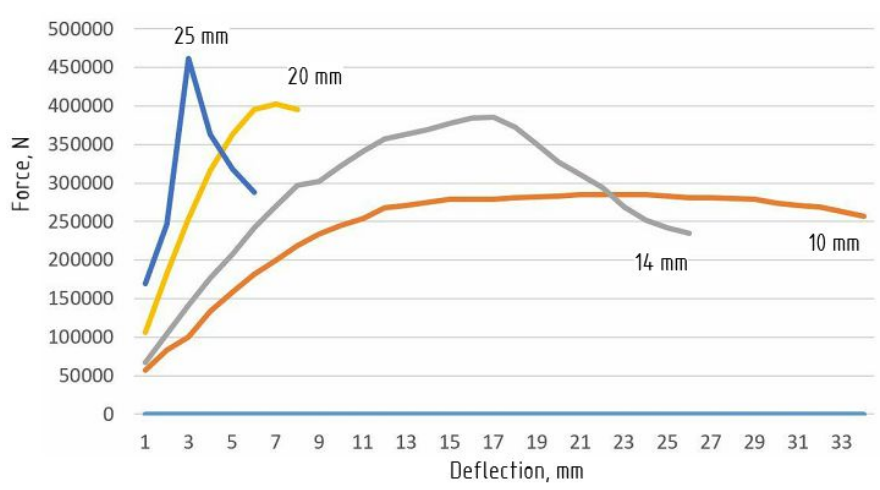

Fig. 6. Force-deflection curves for different numerical slabs

These curves clearly show all three stages of the stress-strain state for each sample. After analyzing the curves shown in the figure 7 it can be concluded that the increase in the total area of the longitudinal reinforcement also leads to the increase in the level of load at which the transition from the first to the second stage of the stress-strain state occurs. The Table 1 represents the results of the finite element experiments with respect of the results of the manual calculations.

Table 1. Results of the finite element compared with the results of the manual calculations

\begin{tabular}{|c|c|c|c|}
\hline $\begin{array}{c}\text { Diameter of tensile } \\
\text { reinforcement of a slab }\end{array}$ & ANSYS & SP 63.13330.2012 & Eurocode 2 \\
\hline 10 & 287 & 135 & 152 \\
\hline 14 & 386 & 135 & 186 \\
\hline 20 & 404 & 135 & 203 \\
\hline 25 & 462 & 135 & 203 \\
\hline
\end{tabular}

If we take the critical strength value obtained in the numerical experiment with slab reinforced by $10 \mathrm{~mm}$ diameter bars as $100 \%$, then the increase in the critical force was $34 \%, 41 \%$, and $61 \%$ for specimens with the $14 \mathrm{~mm}, 20 \mathrm{~mm}$ and $25 \mathrm{~mm}$ diameter longitudinal bars respectively. The failure of the slabs reinforced with 10 and $14 \mathrm{~mm}$ diameter bars occurred simultaneously with the achievement of the yield stress level by the tensile reinforcement bars, while the failure of the slabs reinforced with 20 and $25 \mathrm{~mm}$ diameter bars, occurred due to the compressive failure mechanism, i.e. the tensile reinforcement had not reached the yield stress level. The values of dowel forces affecting the bars were relatively small and equaled to $1 \%, 2 \%, 4 \%$, and $5 \%$ of the failure force for the specimens with $10 \mathrm{~mm}, 14 \mathrm{~mm}, 20 \mathrm{~mm}$, and $25 \mathrm{~mm}$ tension reinforcement bars respectively. The increase in the dowel forces was almost linear. The Figure 7 shows the deformation of a reinforcement bar affected by dowel forces.

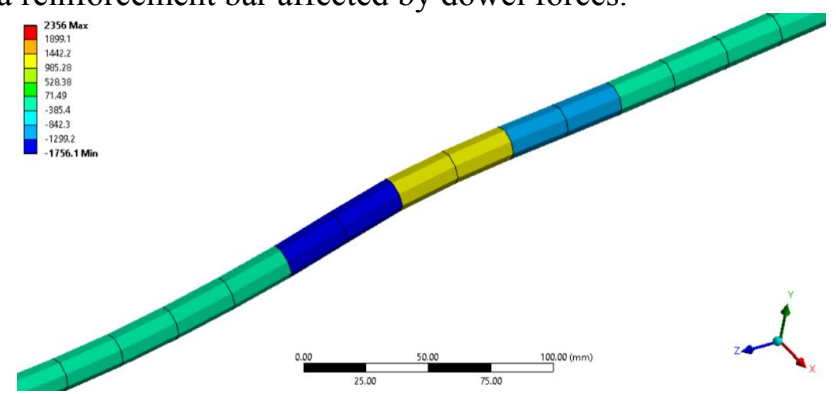

Fig. 7. Deformation of a rebar subjected to dowel forces. 


\section{Conclusions}

Basing on the results obtained by numerical modeling, the following conclusions can be drawn.

1)The longitudinal reinforcement of a reinforced concrete slab without transverse reinforcement subjected to the punching shear significantly influences the loading capacity of the slab. In addition, the longitudinal reinforcement of the slab influences the type of its failure under the punching shear, whether the failure occurs over the compressive zone of the slab or over the tensile zone. This depends on the capacity of the compressive and tensile zones of the flat slab.

2)The dowel action occurs in the longitudinal reinforcement increasing with the bar diameter. However, the values of dowel forces are small and have no significant influence on the punching shear capacity of the slab. The longitudinal reinforcement of the slab has much greater impact on the punching shear capacity, by increasing the strength of uncracked concrete, than the dowel action that is confirmed by various studies $[9,10]$.

3)The relevant building codes of practice provide for estimating the punching shear capacity of a slab with significant safety factor. Moreover, the calculation carried out using the method of determination of the punching shear capacity of a flat slab without transverse reinforcement given in the SP 63.13330.2012 (that does not take into account the influence of longitudinal reinforcement) provides a greater safety factor as compared with the calculation conducted using the method given in Eurocode 2, which, in turn, takes into account the influence of longitudinal reinforcement. This demonstrates the high reliability of structures calculated using methods given in the SP 63.13330.2012, which, however, leads to the underestimation of the real bearing capacity of slabs and reduces the cost effectiveness of the resulting structural solutions.

The work was supported by Act 211 Government of the Russian Federation, contract № 02.A03.21.0006. Thank you to everyone who made useful comments on the text.

\section{References}

1. SP 63.13330.2012 Concrete and won concrete construction. (Moscow 2012)

2. Eurocode 2, Design of Concrete Structures-Part 1-1 EN 1992-1, (Brussels 2004).

3. J. Silfwerbrand, G. Hassanzadeh, International Workshop on Punching Shear Capacity of RC Slabs (Royal Institute of Technology, Stockholm, 2000)

4. D. M. Kotsovos, Mag. of Concrete Research 51(2), 131-141 (1999)

5. S. Kinnunen, H. Nylander, Punching of Concrete Slabs Without Shear Reinforcement, (Royal Institute of Technology, Stockholm, 1960)

6. A. Muttoni, J. Schwartz, IABSE Colloquium 62, 703-708 (1991)

7. P. Sacramento, M. Ferreira, D. Oliveira, G. Melo, Rev. IBRACON Estrut. Mater. 5(5), 659-691 (2012)

8. M. Bartolac, D. Damjanović, I. Duvnjak, Građevinar 67, 771-786 (2015)

9. A. Silantiev, Vestnik MGSU, 1, 71-73 (2009)

10. A. Muttoni, ACI Structural Journal 105, 440-450 (2008) 